\title{
Methanol Dissimilation in Xanthobacter H4-14: Activities, Induction and Comparison to Pseudomonas AM1 and Paracoccus denitrificans
}

\author{
By CRAIG A. WEAVER $\dagger$ AND MARY E. LIDSTROM* + \\ Department of Microbiology, SC-42, University of Washington, Seattle, WA 98195, USA
}

(Received 26 November 1984 ; revised 11 April 1985)

\begin{abstract}
Methanol dissimilatory enzymes detected in the methanol autotroph Xanthobacter H4-14 were a typical phenazine methosulphate-linked methanol dehydrogenase, a $\mathrm{NAD}^{+}$-linked formate dehydrogenase, and a dye-linked formaldehyde dehydrogenase that could be assayed only by activity stains of polyacrylamide gels. This same methanol dehydrogenase activity was found in ethanol-grown cells and was apparently utilized for ethanol oxidation. Formaldehyde dehydrogenase activities were investigated in Paracoccus denitrificans, Xanthobacter H4-14, and Pseudomonas AMl. P. denitrificans contained a previously reported $\mathrm{NAD}^{+}$-linked, GSHdependent activity, but both Xanthobacter H4-14 and Pseudomonas AMI contained numerous activities detected by activity stains of polyacrylamide gels. Induction studies showed that in Xanthobacter H4-14, a $10 \mathrm{kDal}$ polypeptide, probably a dehydrogenase-associated cytochrome $c$, was co-induced with methanol dehydrogenase, but the formaldehyde and formate dehydrogenases were not co-regulated. Analogous induction experiments revealed similar patterns in $P$. denitrificans, but no evidence for co-regulation of dissimilatory activities in Pseudomonas AM1.
\end{abstract}

\section{INTRODUCTION}

In recent years, methylotrophic bacteria have gained the interest of commercial and industrial concerns as potential sources of single cell protein, chemicals and biochemicals (Anthony, 1982). Successful use of these bacteria will most certainly require a detailed knowledge of their physiology, biochemistry and genetics. One aspect of this requirement is an understanding of the regulation exerted upon the genes responsible for the dissimilation and assimilation of onecarbon compounds. Numerous publications have addressed this issue (Cox \& Quayle, 1975; Boulton \& Large, 1977; O'Connor \& Hanson, 1977; O'Connor, 1981; Marison \& Attwood, 1982). Those studies showed that in a variety of methylotrophs the $C_{1}$-associated enzyme activities are present at higher levels in cells grown on methylotrophic substrates when compared to cells grown on heterotrophic substrates, suggesting that these activities are regulated by induction or derepression. Dunstan et al. (1972b), O'Connor \& Hanson (1977) and McNerney \& O'Connor (1980) followed the induction of several $C_{1}$-associated activities in four serine pathway methylotrophs (Pseudomonas AM1, Pseudomonas 3A2, Methylobacterium organophilum and Hyphomicrobium X) upon transfer from heterotrophic to methylotrophic growth. The results from these studies suggested that co-ordinate regulation of certain serine pathway enzymes exists in some of these methylotrophs but not in others. Comparison of methanol dissimilatory activities was not made. Little specific attention has been focused on the regulation of the components of the methanol dissimilatory pathway in methylotrophs despite the fact that these are the preliminary reactions in methylotrophic metabolism and include important energy-yielding reactions.

† Present address: Synergen Associates Inc., 1885 33rd St, Boulder, CO 80301, USA

$\ddagger$ Present address: Center for Great Lakes Studies, 600 E. Greenfield, Milwaukee, WI 53204, USA.

Abbreviations: ADH, aldehyde dehydrogenase; DCPIP, dichlorophenolindolephenol: FADH, formaldehyde dehydrogenase; FDH, formate dehydrogenase; $\mathrm{MeDH}$, methanol dehydrogenase: NBT, nitro blue tetrazolium; PMS, phenazine methosulphate. 


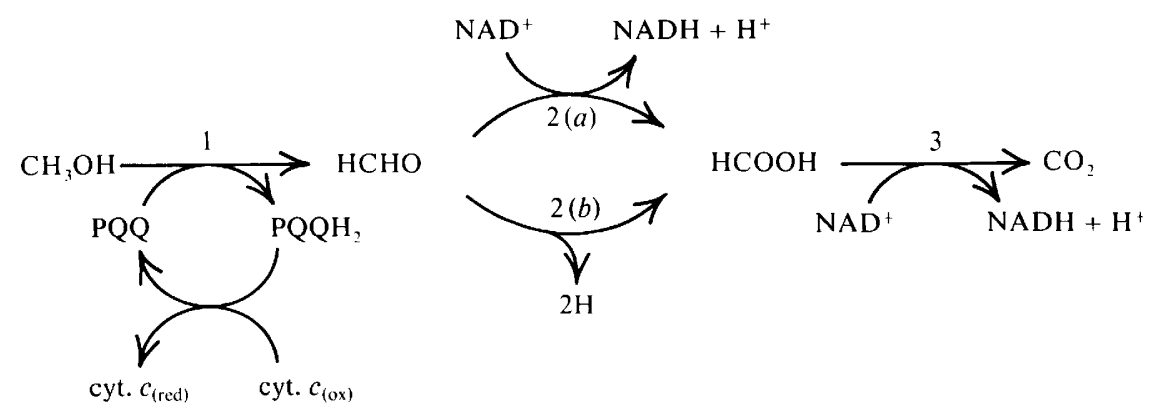

Fig. 1. The methanol dissimilatory pathway of the methylotrophs used in this study. PQQ, pyrryloquinoline quinone: cyt. $c$, cytochrome $c$. For Xanthobacter H4-14, the PQQ and cyt. $c$ have not yet been proven to be present. 1, PMS-linked methanol dehydrogenase. 2, Formaldehyde dehydrogenase: (a) Paracoccus denitrificans (NAD+-linked, GSH-dependent); (b) Pseudomonas AM1, Xanthohacter H4-I4 (identity unknown). 3, Formate dehydrogenase.

Xanthobacter is a recently recognized genus consisting of facultatively chemolithotrophic bacteria, most of which are able to grow on methanol (Wiegel et al., 1978). Xanthobacter strain H4-14 has been described by Lidstrom-O'Connor et al. (1983) and grows on methanol by oxidizing it to $\mathrm{CO}_{2}$ (Fig. 1) and incorporating $\mathrm{CO}_{2}$ via the Calvin-Benson cycle. Thus, this Xanthobacter strain, and presumably the others, belongs to a class of methylotrophs termed 'methanol autotrophs'. A number of diverse autotrophic species able to obtain energy from the oxidation of methanol to carbon dioxide have been described (Anthony, 1982; Kelly \& Wood, 1982; Loginova \& Trotsenko, 1979). Autotrophic growth on methanol is energetically the least efficient of the established methylotrophic pathways (Anthony, 1982). However, it has been suggested that the acquisition by autotrophic bacteria of enzymes capable of converting methanol to carbon dioxide (Fig. 1) is a greater gain in nutritional flexibility than it is a tax on genetics and biochemistry (Sahm et al., 1976).

Methanol dissimilatory activities have been studied in the serine pathway methylotroph Pseudomonas AMl and the autotrophic methylotroph Paracoccus denitrificans. P. denitrificans contains methanol-inducible activities of a phenazine methosulphate (PMS)-linked methanol dehydrogenase $(\mathrm{MeDH})$, a $\mathrm{NAD}^{+}$-linked, GSH-dependent formaldehyde dehydrogenase $(\mathrm{FADH})$ and a NAD ${ }^{+}$-linked formate dehydrogenase (FDH, Fig. 1). In addition, a low level constitutive dye-linked FADH has been detected (Marison \& Attwood, 1980). In Pseudomonas AM1 the pathway is less clear: it contains methanol-inducible PMS-linked MeDH and NAD ${ }^{+}$ linked FDH activities, but the physiologically significant FADH is uncertain (Fig. 1). A dyelinked FADH is present at low activities (Johnson \& Quayle, 1964) but cannot be correlated with methanol growth (Marison \& Attwood, 1980). Formaldehyde oxidation in Pseudomonas AM1 may be effected via tetrahydrofolate intermediates (Marison \& Attwood, 1982; Attwood \& Quayle, 1984) but conclusive evidence is still lacking. In addition to the activities noted above, an NAD ${ }^{+}$-linked activity has been reported (M. M. Attwood, 4th International C-1 Symposium, Minneapolis, 1983). It is not yet known which of these activities is the physiologically significant enzyme.

In this communication we report a study of the activities involved in methanol dissimilation in Xanthobacter H4-14, a new methanol autotroph, Pseudomonas AM1, a serine pathway methylotroph, and $P$. denitrificans, a well studied methanol autotroph. As a prelude to genetic studies, we have examined the pattern of induction of these activities by methanol. Comparison of enzymology and induction patterns has revealed significant differences not only between Xanthobacter H4-14 and the serine pathway methylotroph but also between the two methanol autotrophs.

\section{METHODS}

Organisms and growth conditions. A streptomycin-resistant, rifampicin-resistant, capsule-less derivative of Xanthobacter strain H4-14 (Lidstrom-O'Connor et al., 1983) was used in this study. Pseudomonas AM1 (NCIB 9133) and Paracoccus denitrificans (NCIB 8944) were obtained from J. R. Quayle, University of Bath, UK. 
Bacterial strains were routinely grown on nutrient broth or nutrient agar supplemented with streptomycin sulphate $\left(20 \mu \mathrm{g} \mathrm{m}^{-1}\right)$ or rifampicin $\left(20 \mu \mathrm{g} \mathrm{m}^{-1}\right)$ when required for Xanthobacter $\mathrm{H} 4-14$. Cells for biochemical studies were grown in the minimal salts medium of Harder et al. (1973). Minimal medium for growth of Xanthobacter H4-14 was supplemented with d-biotin $\left(0.2 \mu \mathrm{g} \mathrm{ml}^{-1}\right)$ and the oxygen tension was lowered by incubation under an atmosphere of $75 \%(\mathrm{v} / \mathrm{v})$ helium and $25 \%(\mathrm{v} / \mathrm{v})$ air. Minimal medium for growth of $P$. denitrificans was supplemented with $0.01 \%(\mathrm{w} / \mathrm{v})$ yeast extract (Cox \& Quayle, 1975). For autotrophic growth on methanol, formate or $\mathrm{H}_{2} / \mathrm{CO}_{2}$, the medium was further supplemented with $0.02 \%(\mathrm{w} / \mathrm{v}) \mathrm{KHCO}_{3}$. For growth on $\mathrm{H}_{2} / \mathrm{CO}_{2}, 8 \mu \mathrm{M}-\mathrm{NiCl}_{2}$ was added and the cultures were incubated under an atmosphere of $75 \%(\mathrm{v} / \mathrm{v}) \mathrm{H}_{2} / \mathrm{CO}_{2}$ mixture $\left(6 \mathrm{H}_{2}: 1 \mathrm{CO}_{2}\right)$ and $25 \%$ air. Sodium formate or heterotrophic carbon sources were added to $0 \cdot 1 \%(\mathrm{w} / \mathrm{v})$ and methanol was added to $0.2 \%(\mathrm{v} / \mathrm{v})$. Small batch cultures were incubated on a gyratory shaker at 200 r.p.m. and $30^{\circ} \mathrm{C}$.

The larger scale induction experiments were done in an 181 New Brunswick Microferm fermenter containing 121 of medium at $30^{\circ} \mathrm{C}$. The inocula were concentrates from 1.21 of cells grown to mid-exponential phase on $\mathrm{H}_{2} / \mathrm{CO}_{2}$ (Xanthobacter $\mathrm{H} 4-14$ and $P$. denitrificans) or succinate (Pseudomonas AM1) that had been harvested and washed twice with unsupplemented minimal medium. Aeration was maintained at approximately $50 \mathrm{ml} \mathrm{min}^{-1}$ for Xanthohacter H4-14 or $200 \mathrm{ml} \mathrm{min}{ }^{-1}$ for Pseudomonas AMl and P. denitrificans. Stirring was maintained at approximately 100 r.p.m. For experiments with Xanthohacter H4-14, the initial oxygen tension was lowered by sparging the fermenter with helium (approximately $500 \mathrm{ml} \mathrm{min}^{-1}$ ) for $10 \mathrm{~min}$ with vigorous stirring before inoculation.

Electrophoresis. Sodium dodecyl sulphate-polyacrylamide gel electrophoresis (SDS-PAGE) was done by minor modifications of the method of Laemmli (1970) as detailed by Weaver et al. (1981) except that a uniform acrylamide concentration of $15 \%(\mathrm{w} / \mathrm{v})$ was used and $45 \mu \mathrm{g}$ extract protein were applied per lane. Polypeptides were stained with Coomassie Brilliant Blue R-250. Electrophoresis under non-denaturing conditions (PAGE) was as described above with the following exceptions: (1) the gels were $1.5 \mathrm{~mm}$ thick; (2) SDS was omitted; (3) the separating gel was $6 \%(\mathrm{w} / \mathrm{v})$ acrylamide; (4) the stacking gel was $3 \%(\mathrm{w} / \mathrm{v})$ acrylamide and contained the same buffer system as the separating gel; (5) samples ( $200 \mu \mathrm{g}$ extract protein) were processed by adding a half volume of a loading solution containing $40 \%(\mathrm{w} / \mathrm{v})$ sucrose plus a trace of bromophenol blue and were not heated; (6) electrophoresis was done at $25 \mathrm{~mA}$ at $4{ }^{\circ} \mathrm{C}$

Densitometric scanning of dried acrylamide gels was done with an LK B densitometer (model 2202 Ultroscan) attached to a recording integrator (model 2220; LK B). Conditions for densitometry were optimized for individual polypeptides or activities so that 'densitometer units' are not comparable between different proteins.

Cell extracts and enzyme assays. Cells were harvested $\left(17000 \mathrm{~g}, 10 \mathrm{~min}, 4^{\circ} \mathrm{C}\right)$, washed twice in a half volume of minimal medium, resuspended in a small volume of medium, frozen in a dry ice/ethanol bath and stored at $-70^{\circ} \mathrm{C}$ until needed. After the cells were thawed, deoxyribonuclease I was added to $25 \mu \mathrm{g} \mathrm{ml}^{-1}$ and the cells were disrupted by two passes through a French pressure cell at $20000 \mathrm{lbf}^{-2} \mathrm{n}^{-2}(138 \mathrm{MPa})$. The crude extract was taken as the supernatant fraction after centrifugation at $12000 \mathrm{~g}$ for $10 \mathrm{~min}$. Extracts were stored at $-70^{\circ} \mathrm{C}$ after being frozen drop-wise in liquid nitrogen. Protein was determined by the Lowry method with bovine gamma globulin as a standard.

Methanol dehydrogenase (EC 1.1.99.8: MeDH) was assayed by the method of Anthony \& Zatman (1964) with the following concentration changes: $125 \mathrm{~mm}-\mathrm{Tris} / \mathrm{HCl}(\mathrm{pH} 9 \cdot 0), 50 \mathrm{~mm}-\mathrm{NH}_{4} \mathrm{Cl}, 1 \mathrm{~mm}-\mathrm{KCN}, 2 \mathrm{~mm}-\mathrm{PMS}$, $0 \cdot 1 \mathrm{~mm}$-dichlorophenolindolephenol (DCPIP) and $10 \mathrm{~mm}$-methanol.

Formate dehydrogenase (EC 1.2.1.2; FDH) in extracts of Xanthobacter H4-14 and Pseudomonas AMl was assayed by the method of Johnson \& Quayle (1964) with the following changes: 50 mm-potassium phosphate $(\mathrm{pH} 7 \cdot 0), 0.5 \mathrm{~mm}^{-N A D^{+}}$and $10 \mathrm{~mm}$-sodium formate. For extracts of $P$. denitrificans, $40 \mathrm{~mm}-\mathrm{Tris} / \mathrm{HCl}(\mathrm{pH} 8 \cdot 4)$ replaced the phosphate buffer.

Dye-linked formaldehyde dehydrogenase (FADH) in Pseudomonas AMI was measured by the method of Johnson \& Quayle (1964) with changes as follows: $50 \mathrm{~mm}$-potassium phosphate (pH 7.0), 0.1 mM-DCPIP, 0.1 mM$\mathrm{KCN}$ (to inhibit FDH activity) and $10 \mathrm{~mm}$-formaldehyde. NAD+-linked FADH (EC 1.2.1.1) from $P$. denitrificans was measured as described by Johnson \& Quayle (1964) with the following changes: $50 \mathrm{~mm}$-potassium phosphate ( $\mathrm{pH} \mathrm{8.0)}, 0.5 \mathrm{~mm}-\mathrm{NAD}^{+}, 2.5 \mathrm{~mm}$-reduced glutathione (GSH) and $10 \mathrm{~mm}$-formaldehyde. The assay of FADH in Xanthohacter H4-14 is described in Results.

Methylenetetrahydrofolate dehydrogenase (EC 1.5.1.5) was determined as described by Marison \& Attwood (1982).

The activity of MeDH, FADH, aldehyde dehydrogenase (ADH) and FDH in PAGE gels ('zymograms') was detected as described by Urakami \& Komagata (1981) using nitro blue tetrazolium (NBT) except that $50 \mathrm{mM}-$ Tris/ $\mathrm{HCl}(\mathrm{pH} \mathrm{9.0)} \mathrm{replaced} \mathrm{the} \mathrm{glycine} \mathrm{buffer} \mathrm{for} \mathrm{MeDH}$ detection. All substrates (methanol, formaldehyde, acetaldehyde, propionaldehyde, dodecyl aldehyde or formate) were added at $10 \mathrm{~mm}$. For detection of FADH or ADH activities, PMS was not required but was occasionally included in order to enhance stain development. When PMS was included, MeDH could be detected, presumably due to the initial high $\mathrm{pH}$ in the gel, remaining traces of ammonium ions and the fact that formaldehyde is a substrate for this enzyme in vitro. 
Chemicals. Unless otherwise stated, all reagents were standard reagent grade. The following were obtained from Sigma: PMS, DCPIP, NBT, NAD ${ }^{+}$, paraformaldehyde and protein molecular weight standards for some experiments. Bovine gamma globulin, Coomassie Brilliant Blue and protein molecular weight standards for other experiments were obtained from Bio-Rad. Formaldehyde was prepared by autoclaving $\left[2 \mathrm{~h}, 121^{\circ} \mathrm{C}, 15 \mathrm{lbf}\right.$ in ${ }^{-2}$ $(103.5 \mathrm{kPa})]$ solutions of paraformaldehyde in a sealed vial after sparging of the suspension with helium for $10 \mathrm{~min}$.

\section{RESULTS}

\section{Characteristics of methanol dissimilatory activities in Xanthobacter H4-14}

Methanol dehydrogenase. In Xanthobacter $\mathrm{H} 4-14$ extracts, MeDH activity showed an absolute requirement for high $\mathrm{pH}$ (optimum $\mathrm{pH} 9.0$ ), ammonium ions and the dye PMS. Small primary alcohols and formaldehyde were preferred substrates (Table 1). The molecular mass of the native enzyme was approximately $125 \mathrm{kDal}$, as determined by activity stains of PAGE gels (Table 2). Xanthobacter H4-14 grown on ethanol also possessed high levels of MeDH activity (Table 1). In addition, dye-linked 'ethanol dehydrogenase' from these cells co-migrated with MeDH on PAGE gels (data not shown). No $\mathrm{NAD}^{+}$or NADP+-linked alcohol dehydrogenase activity could be detected in ethanol-grown Xanthobacter $\mathrm{H} 4-14$ when assayed over a pH range of 7.0 to $9 \cdot 0$ using phosphate or Tris buffers, $0.5 \mathrm{~mm}$-pyridine nucleotide and $10 \mathrm{~mm}$-ethanol.

Table 1. Methanol dehydrogenase activity with different alcohols in cell-free extracts of Xanthobacter H4-14 grown on methanol or ethanol

\begin{tabular}{lcc} 
& \multicolumn{2}{c}{ Percentage of activity with methanol* } \\
\cline { 2 - 3 } \multicolumn{1}{c}{ Substrate } & Methanol-grown & Ethanol-grown \\
Methanol & 100 & 100 \\
Ethanol & 91 & 94 \\
$n$-Propanol & 63 & 74 \\
$i$-Propanol & 0 & 0 \\
$n$-Butanol & 47 & 62 \\
$i$-Butanol & 0 & 0 \\
Ethylene glycol & 0 & 0 \\
Glycerol & 0 & 0 \\
Formaldehyde & 100 & ND
\end{tabular}

* $100 \%$ specific activity with methanol was 440 and $200 \mathrm{nmol} \mathrm{min}^{-1} \mathrm{mg}$ protein ${ }^{-1}$ for methanol- and ethanolgrown cells, respectively; ND, not done.

\section{Table 2. Characteristics of the methanol dissimilatory enzymes in Xanthobacter H4-14}

Activities were measured in cell-free extracts except for formaldehyde dehydrogenase, which could only be detected by activity stains on polyacrylamide gels. Approximate sizes were determined by activity stains on a series of polyacrylamide gels of differing acrylamide concentrations, as compared to molecular weight standards.

\section{Characteristic}

Approx. size of native enzyme (kDal)

Requirements for activity

Inhibition by $\mathrm{KCN}$ and $\mathrm{NaN}_{3}$

Electron acceptors

Specific activity (nmol $\mathrm{min}^{-1} \mathrm{mg}$ protein ${ }^{-1}$ )

in cells grown on:

methanol

ethanol

formate

$\mathrm{H}_{2} / \mathrm{CO}_{2}$

succinate or citrate

$\begin{array}{cc}\begin{array}{c}\text { Methanol } \\ \text { dehydrogenase }\end{array} & \begin{array}{c}\text { Formaldehyde } \\ \text { dehydrogenase* }\end{array} \\ 125 & 270 \\ \text { pH } 9 \cdot 0, \mathrm{NH}_{+}^{+} & \mathrm{pH} \mathrm{7.0} \\ - & - \\ \text { PMS } & \text { PMS, NBT }\end{array}$

450
250
45
$7 \cdot 5$
1

$+$

$+$

$+$

$+$

Formate dehydrogenase

70

$+$

$\mathrm{NAD}^{+}, \mathrm{DCPIP}, \mathrm{NBT}$

* Dye-linked, $\mathrm{NH}_{+}^{+-i n d e p e n d e n t . ~}$ 
Presumably, Xanthobacter H4-14 uses the dye-linked MeDH for the initial oxidation of ethanol when growing on this substrate. This same result has been reported for ethanol-grown Pseudomonas AMI (Dunstan et al., 1972a). MeDH activities were present in significant amounts only in cells grown on methanol or ethanol. Lower levels of activity were found in cells grown on formate, $\mathrm{H}_{2} / \mathrm{CO}_{2}$ and heterotrophic substrates (Table 2).

Formaldehyde dehydrogenase. Three apparent FADH activities were detected in Xanthobacter H4-14. A PMS-linked, $\mathrm{NH}_{4}^{+}$-dependent activity that co-migrated with $\mathrm{MeDH}$ activity on zymograms (activity-stained PAGE gels) was detected in cell extracts. In addition, a trace amount of apparent $\mathrm{NAD}^{+}$-linked FADH activity was detected in extracts, but this activity could not be clearly distinguished from FDH activity. This low level of activity was found in formate-grown cells as well as methanol-grown cells at a relatively constant fraction of FDH activity. 'NAD ${ }^{+}$-linked FADH' and FDH activities showed nearly identical induction patterns (not shown). These activities responded similarly to enzyme inhibitors and stimulators (see below), showed similar heat inactivation parameters and co-sedimented on sucrose step gradients (not shown). Furthermore, Xanthobacter FDH and commercially available Pseudomonas oxalaticus FDH showed low levels of reactivity on zymograms with all formaldehyde preparations tested. We concluded that the trace levels of NAD+-linked FADH activity in Xanthobacter H4-14 were due either to small amounts of formate in the formaldehyde preparations or low levels of formaldehyde utilization by the FDHs.

Except for the activity attributable to $\mathrm{FDH}$, no formaldehyde-dependent, $\mathrm{NH}_{4}^{+}$-independent reduction of PMS, NBT or DCPIP could be convincingly demonstrated in crude extracts of Xanthobacter $\mathrm{H} 4-14$ by spectrophotometric procedures and with assay $\mathrm{pH}$ values ranging from 6.5 to $9 \cdot 0$. Further attempts were made to detect this activity with fractionated extracts. Membrane preparations obtained by centrifugation of crude extracts at $50000 \mathrm{~g}$ for $1 \mathrm{~h}$ contained no detectable activity in either particulate or soluble fractions. In addition, batchwise DEAE-cellulose fractions of crude extracts contained no detectable activity. However, it was possible to detect a third FADH activity distinct from $\mathrm{MeDH}$ and FDH (Table 2) by activity stains of PAGE gels. This activity was stimulated by but did not require PMS, was unaffected by reduced glutathione $(5 \mathrm{mM})$, was approximately $270 \mathrm{kDal}$ in size, and was most reactive towards longer-chain aldehydes (acetaldehyde, propionaldehyde and dodecylaldehyde). This activity was not specifically associated with methanol-grown Xanthobacter H4-14, being found at similar levels under all growth regimens examined (Table 2).Its possible role in methanol dissimilation is discussed later. In addition, an 'aldehyde dehydrogenase' (ADH) activity was detected on PAGE gels that reacted with longer-chain aldehydes but not with formaldehyde. This enzyme was approximately $200 \mathrm{kDal}$ in size and was distinct from the dyelinked FADH as well as the other FADH activities mentioned above.

Formate dehydrogenase. Oxidation of formate by Xanthobacter H4-14 was accomplished by a $\mathrm{NAD}^{+}$-utilizing FDH that was highly specific for formate and tightly regulated. FDH was detected only in extracts from methanol- and formate-grown cells (Table 2). DCPIP and NBT also served as electron acceptors. The activity in crude cell extracts was sensitive to cyanide $(7 \%$ activity at $0.5 \mathrm{~mm}-\mathrm{KCN})$ and azide $\left(25 \%\right.$ activity at $\left.0.5 \mathrm{~mm}-\mathrm{NaN}_{3}\right)$ but insensitive to $0.05 \mathrm{~mm}$ dipyridyl, $0.4 \mathrm{~mm}-\mathrm{CuSO}_{4}$ and $0.05 \mathrm{~mm}-\mathrm{FeSO}_{4}$. Thiol reagents (2-mercaptoethanol, DTT and GSH) were not required for activity or short term stability, but these chemicals typically stimulated FDH activity by $25-50 \%$. Analysis of zymograms revealed a size of approximately $105 \mathrm{kDal}$ for the FDH activity.

\section{Induction of methanol dissimilatory activities in Xanthobacter H4-14}

Figs 2 and 3 show the pattern of cell growth, polypeptides and enzyme induction when hydrogen-grown Xanthobacter cells were diluted and exposed to methanol. Data for the FADH and $\mathrm{ADH}$ activities and two induced polypeptides (Fig. $3 b, c$ ) were taken from the PAGE zymograms and SDS-PAGE analysis shown in Fig. 2. The levels of MeDH and FDH were initially low or undetectable in hydrogen-grown cells and then were seen to increase dramatically. These activities peaked in the mid-exponential phase of growth, albeit at different times, and then declined precipitously as the culture neared the end of its growth phase. Both the 


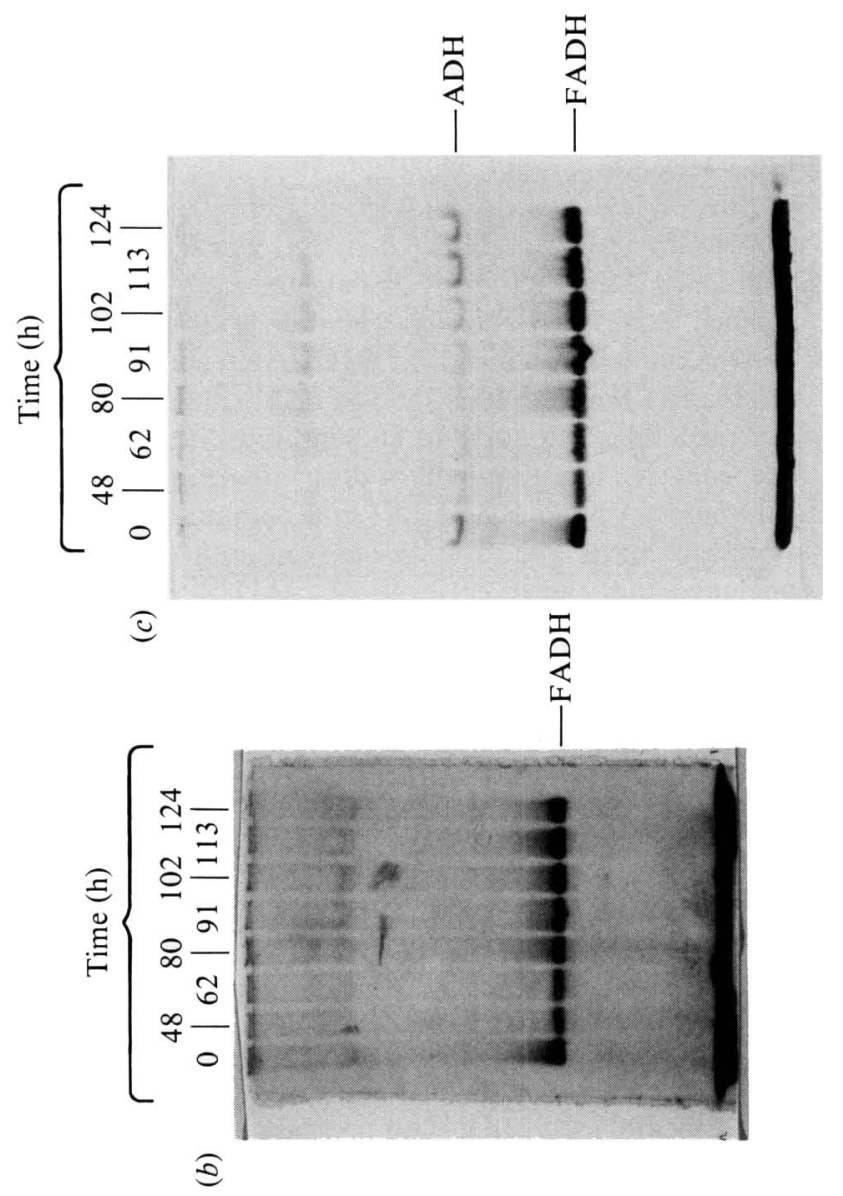

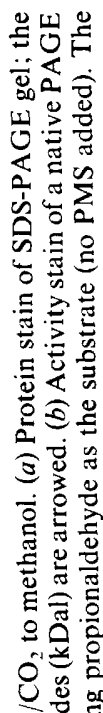

造

语骂焉

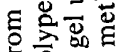

영밍

要过迹

政的

政

过总

仓

劳焉悲

कि 政

ป

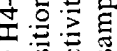

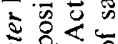

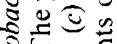

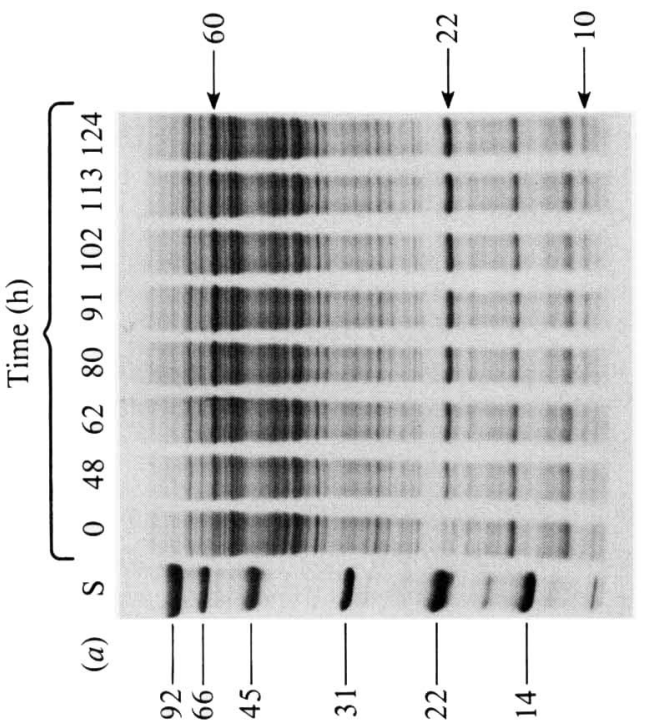

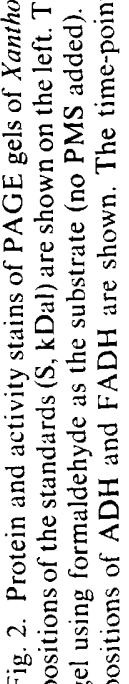



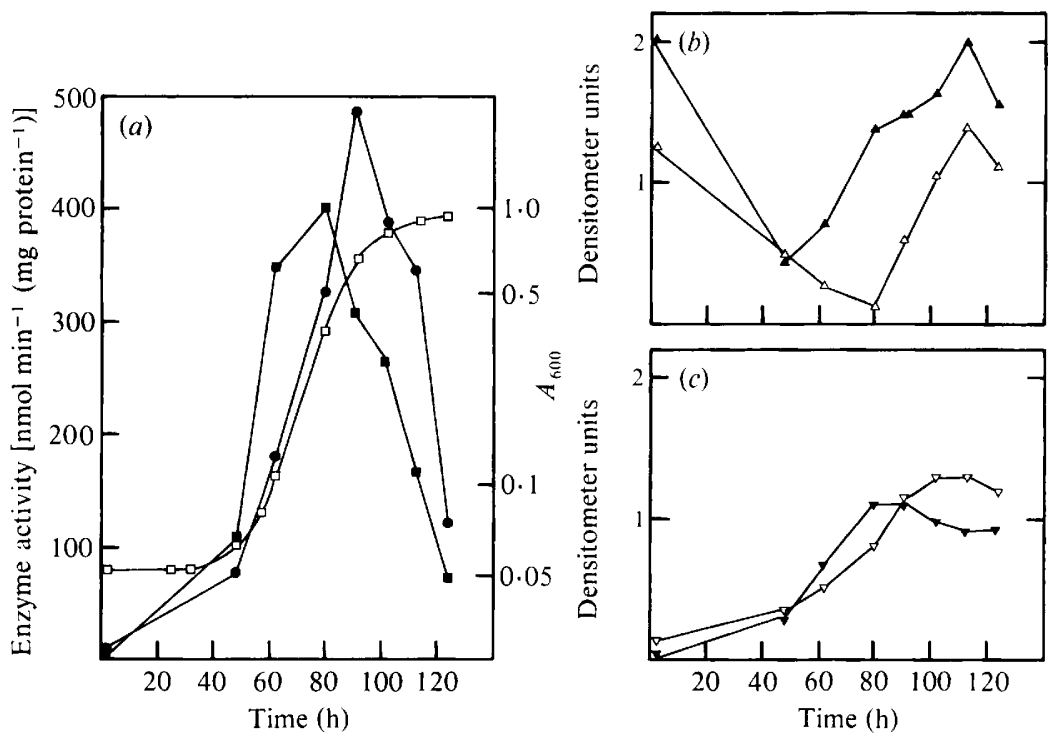

Fig. 3. Profiles of growth and $\mathrm{C}_{1}$-associated activities and polypeptides in Xanthobacter $\mathrm{H} 4-14$ from the induction experiment shown in Fig. 2. (a) Spectrophotometrically determined activities of methanol dehydrogenase ( $O$ ) and formate dehydrogenase $(\boldsymbol{G})$ and absorbance at $600 \mathrm{~nm}(\square)$. (b) Values derived from densitometer scans of PAGE gels stained for activity of formaldehyde dehydrogenase $(\boldsymbol{A})$ and aldehyde dehydrogenase $(\triangle)$. (c) Values derived from densitometer scans of SDS-PAGE protein gels: $\nabla, 10 \mathrm{kDal}$ polypeptide: $\nabla, 22 \mathrm{kDal}$ polypeptide.

FADH and ADH activities were initially high in hydrogen-grown cells but decreased significantly upon exposure of the cells to methanol. Both activities subsequently increased as the culture began to grow on methanol, but only the increase in FADH activity approximated the increases in cell density and MeDH and FDH activities.

Marison \& Attwood (1982) suggested that oxidation of formaldehyde could involve tetrahydrofolate derivatives. Levels of methylenetetrahydrofolate dehydrogenase, a key enzyme in the proposed pathway, decreased slightly during the course of this induction experiment (data not shown). It is unlikely, therefore, that a tetrahydrofolate-dependent formaldehyde oxidation pathway contributes significantly to methanol dissimilation in Xanthobacter H4-14.

SDS-PAGE analysis of the crude extracts revealed three polypeptides $(60,22$ and $10 \mathrm{kDal})$ that clearly increased in amount as the cells adapted to growth on methanol (Fig. $2 a$ ). In other methylotrophs, MeDH consists of a dimer of a $60-70 \mathrm{kDal}$ polypeptide, and it is commonly seen as a major protein in methanol-grown cells (Anthony, 1982). Therefore, the prominent $60 \mathrm{kDal}$ band in Fig. 2(a) may represent the subunit of MeDH. The increase in the amount of this polypeptide approximately paralleled $\mathrm{MeDH}$ activity for the first $80 \mathrm{~h}$, but the decrease in $\mathrm{MeDH}$ activity observed after $80 \mathrm{~h}$ was not reffected in a concomitant decrease in the intensity of this band. These results suggest the decrease in $\mathrm{MeDH}$ activity was due to post-translational events.

The induction patterns of the 22 and $10 \mathrm{kDal}$ polypeptides (Figs $2 a$ and $3 c$ ) were roughly similar to that of the MeDH polypeptide. These two smaller polypeptides are similar in size to the two soluble $c$-type cytochromes associated with MeDH activity in Pseudomonas AMI and Methylophilus methylotrophus (O'Keeffe \& Anthony, 1980; Beardmore-Gray et al., 1982). In Pseudomonas AM1, the larger cytochrome $c$ is thought to accept electrons directly from $\mathrm{MeDH}$, but the role of the smaller cytochrome is unclear (Beardmore-Gray et al., 1983). However, the $22 \mathrm{kDal}$ polypeptide of Xanthobacter H4-14 was not a prominent component of ethanol-grown cells which would be expected to contain the full complement of MeDH-associated polypeptides (data not shown). The $10 \mathrm{kDal}$ polypeptide was present in these cells. Thus, it was not clear whether these polypeptides were MeDH-associated cytochromes. 
Table 3. Aldehyde dehydrogenase activities detected in three methylotrophs

Aldehyde dehydrogenase

NAD+-linked, GSH-dependent*

NAD ${ }^{+}$-linked, GSH-independent*

Dye-linked, $\mathrm{NH}_{+}^{+}$-dependent $(\mathrm{MeDH})^{*} \dagger$

Dye-linked, $\mathrm{NH}_{4}^{+}$-independent formaldehyde activity $(\mathrm{FADH}) \dagger$

Little or no activity with formaldehyde (ADH)
Xanthobacter Pseudomonas H4-14

AM 1

-
-+
+
+

Paracoccus denitrificans

NT, Not tested.

* Assayed in cell-free extracts.

$\uparrow$ Detected by activity stains of polyacrylamide gels.

¥ Low levels were detected, but were apparently due to traces of formate in the formaldehyde preparations.

\section{Aldehyde dehydrogenases in Pseudomonas AMI}

The ADHs detected in Pseudomonas AM1 are summarized in Table 3. The dye-linked FADH activity reported by Marison \& Attwood (1980) was detected in low levels in cell extracts. We were unable to detect the NAD ${ }^{+}$-linked FADH reported by M. M. Attwood at the 4th C-1 Symposium, Minneapolis, 1983, over a $\mathrm{pH}$ range of $6 \cdot 5-9 \cdot 0$. The reason for our inability to detect this activity is unknown, but may be due to differences in methods of cell breakage or growth conditions. A low level NAD+-linked activity was detected but, as was the case with Xanthobacter H4-14, this activity could not be distinguished from the FDH and may have been due to traces of formate in our formaldehyde preparations. However, development of zymograms with formaldehyde or propionaldehyde revealed five proteins with strong aldehydereducing activities and numerous proteins with minor activities (Fig. $4 b, c$ ). Characteristics of the $\mathrm{ADH}$ activities detected are listed in Table 3. A protein that co-migrated with $\mathrm{MeDH}$ activity was clearly the most prominent ADH in crude extracts, but the physiological role of $\mathrm{MeDH}$ in formaldehyde oxidation is probably not significant (Marison \& Attwood, 1982; Attwood \& Quayle, 1984). Two proteins, designated FADH-1 and FADH-2, showed significant activity with formaldehyde. These and ADH-2 showed strong activity with propionaldehyde. An additional protein, ADH-1, showed weaker propionaldehyde dehydrogenase activity. Based on relative staining intensities, FADH-2 was the most specific for formaldehyde.

\section{Induction in Pseudomonas AMI}

Analysis of changes in the methanol dissimilatory enzymes and in total polypeptides as Pseudomonas AMl was switched from growth on succinate to growth on methanol is presented in Figs 4 and 5. MeDH activity increased about sixfold during the course of the experiment, and the $60 \mathrm{kDal} \mathrm{MeDH}$ polypeptide increased to a high level. Enzymically-measured FADH activity decreased with growth on methanol. This finding is consistent with a previous suggestion that this activity may not be involved in methanol dissimilation (Marison \& Attwood, 1982). Fig. 5 includes induction patterns generated from densitometric scanning of the FADH-1 and FADH-2 bands. Except for early time-points, the FADH-2 pattern was similar to the pattern of FADH activity measured spectrophotometrically. The pattern of initial activity increase followed by a slight decrease to a stable level seen with FADH-1 was the type of change expected for an enzyme involved in methanol dissimilation.

FDH activity increased from an undetectable level in succinate-grown Pseudomonas AM1 to a broad peak in the early to mid-exponential phase of growth followed by a slow decrease in activity. The initial rate of increase of FDH activity was similar to that for MeDH activity.

Examination of the Pseudomonas AMI extracts by SDS-PAGE clearly showed three inducible polypeptides (Fig. $4 a$ ). These were probably the $\mathrm{MeDH}$ subunits $(60 \mathrm{kDal})$, cytochrome $c_{\mathrm{L}}$ (20 kDal) and cytochrome $c_{\mathrm{H}}(10 \mathrm{kDal})$, as described by O'Keeffe and Anthony (1980). 

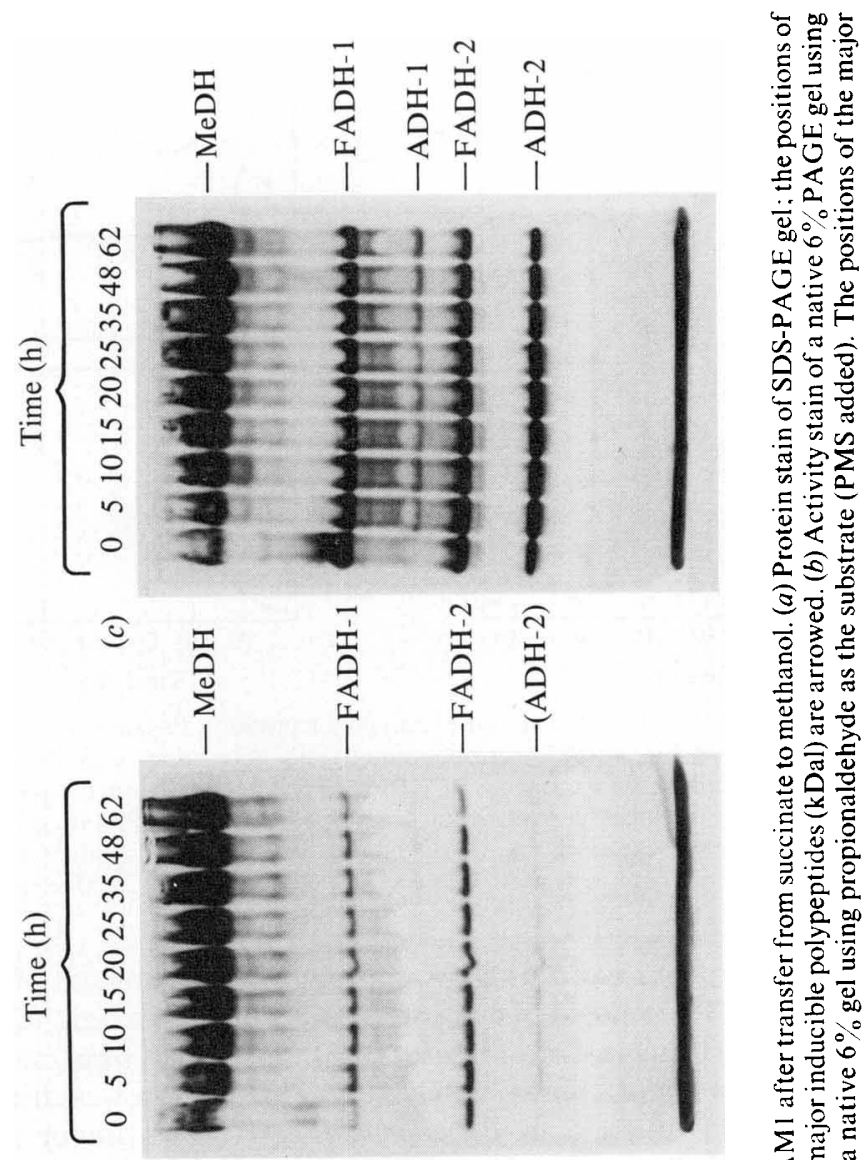

छ요

棕

要票

苋艺

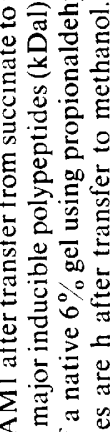

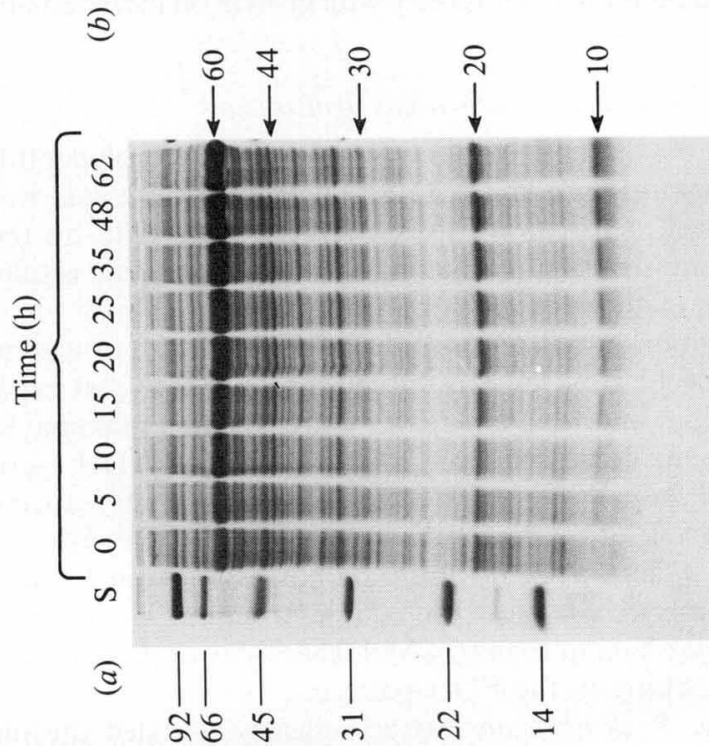

导

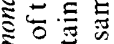

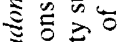

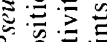

$5 \div$

品

U灾昰

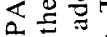

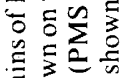

政

会市

票

咅五

$\Xi \dot{s}$

要

昰空

○ 吾

过氠 

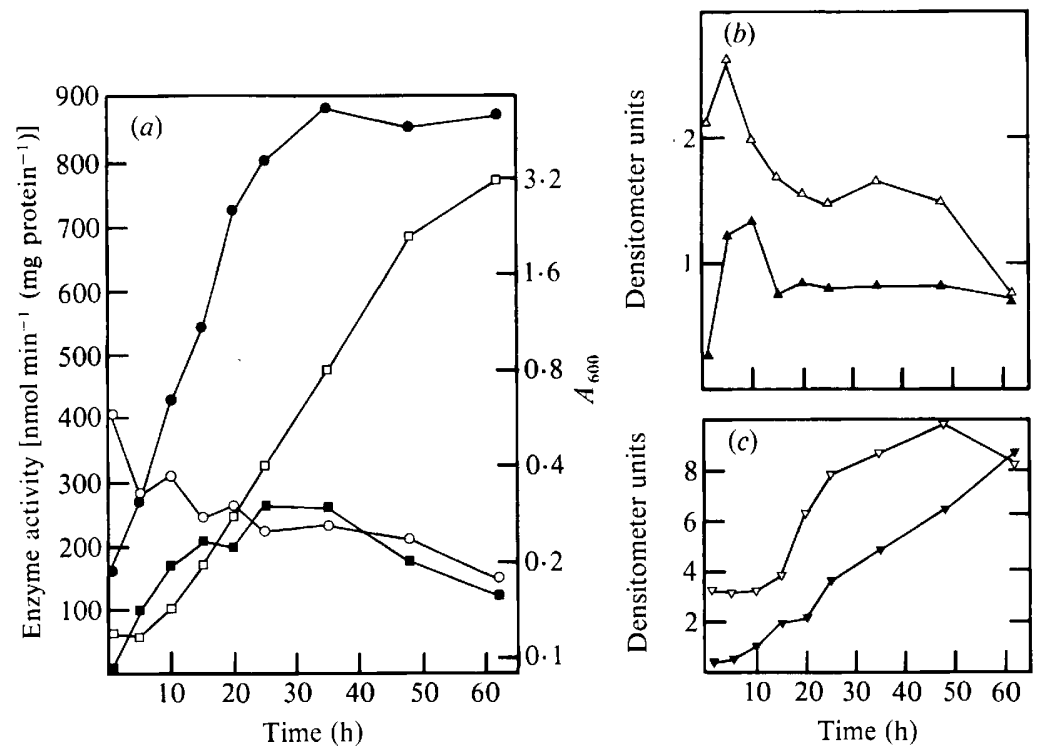

Fig. 5. Profiles of growth and $\mathrm{C}_{1}$-associated activities and polypeptides in Pseudomonas AMl from the induction experiment shown in Fig. 4. (a) Spectrophotometrically determined activities of methanol dehydrogenase $(O)$, formaldehyde dehydrogenase $(\mathrm{X} 10)(\mathrm{O})$ and formate dehydrogenase $(\boldsymbol{D})$ and absorbance at $600 \mathrm{~nm}(\square)$. (b) Values derived from densitometer scans of PAGE gels stained for activity of formaldehyde dehydrogenases: $\triangle, F A D H-1 ; \triangle, F A D H-2$. (c) Values derived from densitometer scans of SDS-PAGE protein gels: $\boldsymbol{\nabla}, 10 \mathrm{kDal}$ polypeptide; $\nabla, 20 \mathrm{kDal}$ polypeptide.

Quantification of the cytochrome $c$ bands is shown in Fig. 5(c): the amount of cytochrome $c_{\mathrm{H}}$ increased steadily with time. The amount of cytochrome $c_{\mathrm{L}}$, which is thought to be most closely associated with MeDH (Beardmore-Gray et al., 1983), increased from a relatively high background level only after a lag of approximately $10 \mathrm{~h}$. This pattern was distinctly different from the pattern of MeDH induction in Pseudomonas AM1. Two minor polypeptides of approximately 44 and $30 \mathrm{kDal}$ increased in intensity with growth on methanol, but their identity is unknown.

\section{Induction in Paracoccus denitrificans}

The induction of the methanol dissimilatory activities and related polypeptides in hydrogengrown $P$. denitrificans is shown in Figs 6 and 7. Interpretation of these data was made difficult since the initial increase in cell density was apparently due to growth on the trace amount $(0.01 \%)$ of yeast extract in the medium. Omission of this supplement resulted in long and unpredictable lag times for growth on methanol.

$\mathrm{MeDH}$ activity increased upon initial exposure to methanol from an undetectable level in hydrogen-grown $P$. denitrificans to a low level as the cells grew on the yeast extract. After about $30 \mathrm{~h}$, growth on methanol began and $\mathrm{MeDH}$ activity increased to a maximal level during late exponential growth and then decreased as growth ceased. FADH activity increased immediately upon exposure of the cells to methanol and continued to increase during growth on methanol, reaching a peak during late exponential growth. This activity also decreased toward the latter stages of the growth cycle. Since $P$. denitrificans possesses a well defined formaldehydeoxidizing activity, no zymograms were made of the samples from this induction experiment. The pattern of FDH activity was very similar to that of $\mathrm{MeDH}$ activity except for the initial period of $\mathrm{MeDH}$ increase which was lacking in the FDH pattern.

SDS-PAGE analysis of the $P$. denitrificans extracts clearly revealed the induction of five polypeptides of approximately $64,44,22,20$ and $14 \mathrm{kDal}$ (Fig. 6). The strongly induced $64 \mathrm{kDal}$ polypeptide may be the MeDH subunit. However, Bamforth \& Quayle (1978) reported a subunit size of $76 \mathrm{kDal}$ for $\mathrm{MeDH}$ purified from this same strain of $P$. denitrificans. The reason for this 


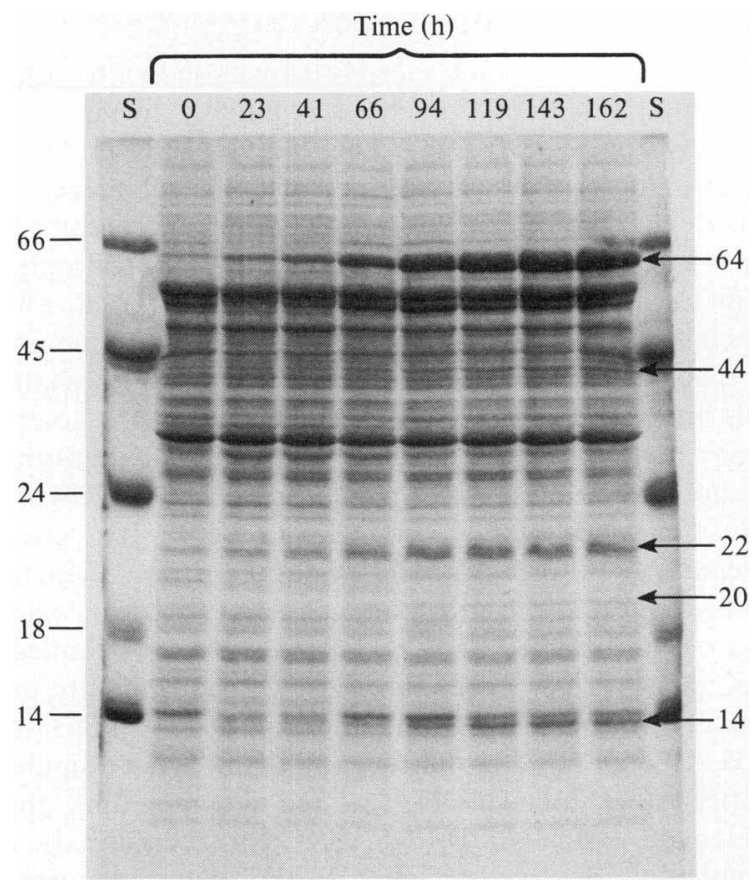

Fig. 6. Protein SDS-PAGE patterns of Paracoccus denitrificans samples after transfer from $\mathrm{H}_{2} / \mathrm{CO}_{2}$ to methanol. The positions of the standards $(\mathrm{S}, \mathrm{kDal})$ are shown on the left and those of the major inducible polypeptides $(\mathrm{kDal})$ are arrowed. The time-points of samples are $\mathrm{h}$ after transfer to methanol.
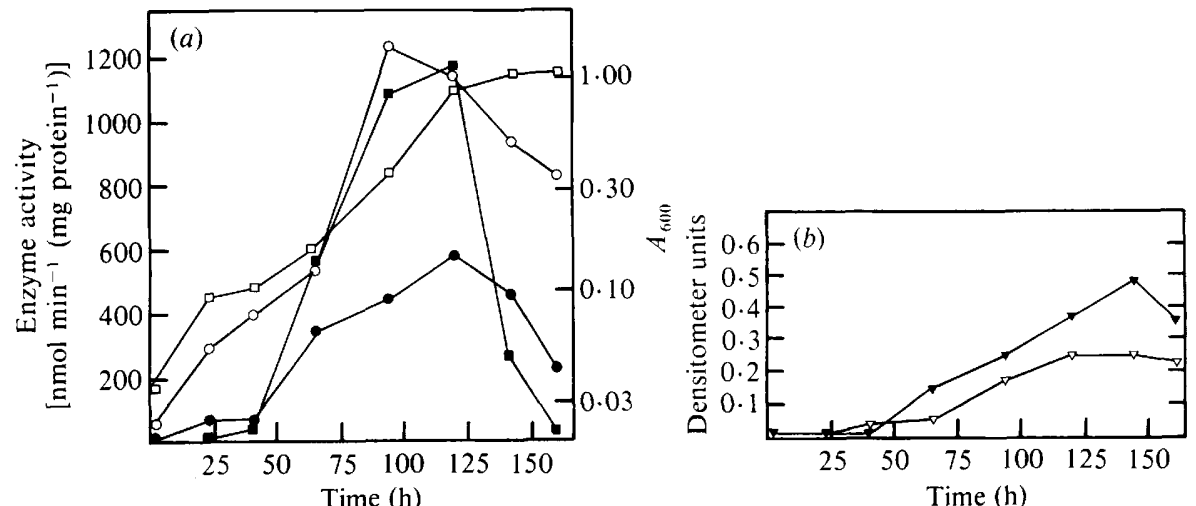

Fig. 7. Profiles of growth and $\mathrm{C}_{1}$-associated activities and polypeptides in Paracoccus denitrificans from the induction experiment shown in Fig. 6. (a) Spectrophotometrically determined activities of methanol dehydrogenase (O), formaldehyde dehydrogenase $(\bigcirc)$ and formate dehydrogenase (X10) ( $\mathbf{Q})$ and absorbance at $600 \mathrm{~nm}(\square)$. (b) Values derived from densitometer scans of SDS-PAGE protein gels: $\boldsymbol{\nabla}$, $14 \mathrm{kDal}$ polypeptide: $\nabla, 20 \mathrm{kDal}$ polypeptide.

size discrepancy is unknown, but it may have been due to the difference in the methods used. By analogy to other methylotrophs, two of the three smaller induced polypeptides $(22,20$ and $14 \mathrm{kDal})$ probably represented methanol-specific $c$-type cytochromes. Beardmore-Gray et al. (1983) purified two cytochromes $c$ from $P$. denitrificans and showed that one reacted specifically with MeDH. Moreover, Van Verseveld \& Stouthamer (1978) identified a methanol-inducible cytochrome $c$ from spectral data. However, molecular sizes were not determined. The induction pattern of the $20 \mathrm{kDal}$ polypeptide, and to a lesser extent that of the $14 \mathrm{kDal}$ polypeptide, was similar to the pattern of MeDH activity (Fig. 7). The identities of the other methanol-inducible polypeptides are unknown. 


\section{DISCUSSION}

The facultative chemolithotroph Xanthobacter H4-14 was shown to contain three methanol dissimilatory activities: methanol dehydrogenase $(\mathrm{MeDH})$, formaldehyde dehydrogenase (FADH) and formate dehydrogenase (FDH). The MeDH was similar to most other such enzymes in methylotrophs in terms of assay requirements, molecular size, and apparent subunit composition. It seems likely that, as in other MeDHs, this enzyme contains the pyrryloquinoline quinone co-factor and passes electrons to a small, soluble $c$-type cytochrome. $\mathrm{MeDH}$ was tightly regulated, being present in significant amounts only when required, i.e. during growth on methanol or ethanol. A change in growth substrates from $\mathrm{H}_{2} / \mathrm{CO}_{2}$ to methanol resulted in a 65 fold increase in $\mathrm{MeDH}$ specific activity. The $60 \mathrm{kDal} \mathrm{MeDH}$ subunit was the major polypeptide in methanol-grown cells and represented approximately $10 \%$ of the soluble protein.

As is the case for many methylotrophic bacteria, the nature of the formaldehyde-oxidizing component of the methanol-dissimilatory pathway of Xanthobacter H4-14 is not absolutely clear. Three possibilities were identified: MeDH, FADH and ADH. It is generally assumed that $\mathrm{MeDH}$ plays no significant role in formaldehyde oxidation in vivo. Evidence includes the fact that $\mathrm{MeDH}$ appears to be a periplasmic enzyme that vectorally translocates methanol-derived formaldehyde to the cytoplasm where, it is hypothesized, it must be acted upon by a distinct FADH (Jones et al., 1982; Kasprzak \& Steenkamp, 1983). In addition, the high $K_{\mathrm{m}}$ of MeDH for formaldehyde (Marison \& Attwood, 1982) and the ability of MeDH mutants to grow on methylamine (Marison \& Attwood, 1980) would suggest that it is not a significant FADH in vivo. Of the two ADH activities (other than MeDH) detected in zymograms, only one (FADH) was reactive toward formaldehyde. Both FADH and ADH oxidized aliphatic aldehydes and were not uniquely found in methanol-grown cells. Therefore, they may be required for non- $\mathrm{C}_{1}$-related reactions. The inability to detect $\mathrm{ADH}$ activity spectrophotometrically in crude extracts is curious. It is possible that the gels stabilized activity, or provided a more sensitive indicator of low activities, in the absence of background reactions. Alternatively, the lack of detectable activity may have been due to the presence of inhibitors that were separated from the enzyme upon electrophoresis. It was not possible to determine whether pyridine nucleotides could serve as electron acceptors for the FADH or ADH.

Two pieces of information suggest that the FADH is indeed involved in methanol dissimilation in Xanthobacter H4-14. First, the increase in FADH activity during methanol induction reflected cell growth. Second, a regulatory mutant of Xanthobacter H4-14 has been isolated that produces little or no FADH in the presence of methanol, and exhibits a methanolsensitive phenotype probably due to formaldehyde toxicity (C. A. Weaver \& M. E. Lidstrom, unpublished results). Now that a gel assay has been developed, it will be possible to purify both FADH and ADH and characterize them more fully.

If FADH is indeed a part of the methanol dissimilatory pathway, then the initial dramatic decrease in activity upon transfer of hydrogen-grown cells to methanol is an unusual feature. The pattern is reminiscent of the auto-induction mechanism seen in the case of bacterial luciferase (Nealson, 1977). However, preliminary experiments have shown that the pattern of FADH regulation in Xanthobacter H4-14 was not simply due to culture dilution and subsequent outgrowth or to a change in energy source (C. A. Weaver \& M. E. Lidstrom, unpublished results). It is not known if this phenomenon is a function of pre-growth on hydrogen, dilution into a methanol-containing medium, or both. It is possible that the level of FADH activity is determined by the steady-state level of formaldehyde or another key aldehyde, which would be dependent upon the activity of the aldehyde-producing and aldehyde-consuming reactions. Alternatively, it may be regulated in a general way by the growth rate or nutritional state of the cells, hypotheses that can only be tested using continuous culture.

Anthony (1982) noted that for many methylotrophs FDH is the only readily demonstrable source of reduced pyridine nucleotides. This is apparently the case for Xanthobacter H4-14. The FDH from Xanthobacter H4-14 was specific for formate and passed electrons to NAD ${ }^{+}$, DCPIP or NBT, but not NADP ${ }^{+}$. It is distinct from the FDH purified from Pseudomonas AM1 in terms of pH preference and sensitivity to cuprous and ferrous salts (Johnson \& Quayle, 1964) and is considerably smaller than the FDH obtained from Pseudomonas oxalaticus (Muller et al., 1978). The difference in properties among these enzymes that perform the same function is intriguing. 
The FDH in Xanthobacter H4-14 was tightly regulated, even more so than the MeDH. High levels of activity were found only in methanol- and formate-grown cells, while cells grown on other substrates contained no detectable activity.

For Xanthobacter H4-14, induction studies suggested that the MeDH and the $10 \mathrm{kDal}$ polypeptide, which may represent the $\mathrm{MeDH}$-associated cytochrome $c$, were co-regulated. However, the FADH and FDH activities were not. Since formate-grown cells contain only low levels of $\mathrm{MeDH}$ and no detectable $10 \mathrm{kDal}$ polypeptide, methanol is probably the inducer for the $\mathrm{MeDH}$ and its associated functions, but formate or a derivative is probably the inducer for FDH. FADH regulation has been discussed above.

Dunstan et al. (1972b) and McNerney \& O'Connor (1980) presented evidence for co-ordinate regulation of several serine pathway enzymes in Pseudomonas AM1, although MeDH appeared to be regulated separately. We have shown that the methanol dissimilatory functions in Pseudomonas AMl are not co-regulated. $\mathrm{MeDH}$ and FDH appeared to be induced at similar rates, but formate-grown Pseudomonas AMl contained only uninduced levels of MeDH (unpublished results), suggesting that this apparent relationship was circumstantial.

It is interesting to note the numerous FDH activities in Pseudomonas AMl detected by activity stains. Since it is unlikely that the spectrophotometrically-determined (dye-linked) FADH is involved in methanol dissimilation due to its low activity and lack of methanoldependent control, one of the stained activities, perhaps FADH-1, may be the true, physiologically active enzyme. The in vivo electron acceptors for these activities may be either $\mathrm{NAD}^{+}$, cytochromes or unknown acceptors. Biochemical and mutant analysis of these activities should resolve the question of formaldehyde oxidation in Pseudomonas AM1.

In contrast to the induction experiments with Xanthobacter H4-14 and Pseudomonas AM1, those with $P$. denitrificans revealed several potential examples of co-ordinate regulation. The induction patterns for MeDH and FDH were similar but, as in the cases of Xanthobacter H4-14 and Pseudomonas AM1, formate-grown $P$. denitrificans had only uninduced levels of MeDH (not shown). The patterns of induction for polypeptides of 14,20,24 and $44 \mathrm{kDal}$ were all similar to those for $\mathrm{MeDH}$ and $\mathrm{FDH}$. As indicated above, one or two of the smaller polypeptides may represent $\mathrm{MeDH}$-specific $c$-type cytochromes and, thus, may be co-ordinately regulated with $\mathrm{MeDH}$. The other polypeptides may be associated with FDH. Definition of the physical relationships among the genes for these activities and polypeptides will require detailed genetic analysis.

The pattern of induction for the $P$. denitrificans GSH-dependent FADH was especially interesting in that it was apparently induced immediately by methanol in contrast to the delayed induction of $\mathrm{MeDH}$ and FDH caused by initial growth on yeast extract. This finding suggests not only independent regulation of FADH by methanol but also the absence of a "catabolite repression' factor that may control MeDH and possibly FDH gene expression.

Although induction patterns of this type provide important information on regulation of enzyme activities at the whole cell level, they provide little insight into genetic organization or transcriptional regulation. Enzyme activity in cell extracts is a result of transcriptional, translational and effector-mediated regulation. Therefore, measuring enzyme activities without concomitant analyses of the protein and mRNA provides little information concerning these three levels of regulation. In addition, it is known in $E$. coli that different genes present in the $t r p$ operon are co-transcribed but are expressed in the cell at different levels due to differential termination events (Platt, 1981). Therefore, the presence or absence of co-regulation cannot be taken as evidence for or against the presence of operons. Detailed genetic analysis, which is now available in Xanthobacter H4-14 (C. A. Weaver \& M. E. Lidstrom, unpublished results) and Pseudomonas AMl (Fulton et al., 1984) will be necessary to determine the molecular details of regulation of these methanol dissimilatory functions.

Three general points of interest can be drawn from the study of these methylotrophs. First, significant differences exist in the enzymology and regulatory patterns for the methanol dissimilatory activities. In particular, the differences between the two methanol autotrophs Xanthobacter H4-14 and Paracoccus denitrificans are striking. Analogous regulatory differences among other methylotrophs have been noted previously (McNerney \& O'Connor, 1980).

Second, the three bacteria have different ways of coping with a common problem, 
formaldehyde removal. In the autotrophs, formaldehyde is produced mainly by MeDH and is removed by FADH. In Pseudomonas AMI, removal reactions include both FADH and the reactions of the serine pathway. Xanthobacter H4-14 apparently does not cope well with formaldehyde and the fact that it grows slowly on methanol after a long lag may be due to formaldehyde toxicity. Formaldehyde-detoxifying (FADH) activity initially decreased in response to methanol, suggesting that formaldehyde could build up due to $\mathrm{MeDH}$ activity. This organism was isolated from a low-nutrient lake as a co-culture with a methanotroph in which it apparently grew on low levels of methanol excreted by the methanotroph (Lidstrom-O'Connor et al., 1983). Since this strain was adapted to growth at low methanol concentrations, it is perhaps not surprising that it has not developed efficient means for dealing with high methanol concentrations. It is surprising, however, that no pyridine-nucleotide coupled formaldehyde oxidation could be detected since this deficiency would result in inefficient autotrophic growth. It is possible that the FADH detected on PAGE gels is pyridine-nucleotide linked in vivo. $P$. denitrificans not only has an $\mathrm{NAD}^{+}$-linked FADH activity but also this activity was induced rapidly in response to methanol, thus apparently solving any potential problems of formaldehyde toxicity during growth at high methanol concentrations. Pseudomonas AM1 contains a partially constitutive $\mathrm{MeDH}$ so that formaldehyde will be produced from methanol immediately. However, it also has partially constitutive FADH activities and low levels of the serine pathway enzymes which should transform formaldehyde before it reaches toxic levels. The partially constitutive MeDH and FADH activities in Pseudomonas AMI may allow this organism to respond rapidly to methanol in the environment and out-compete less responsive organisms.

Third, the commercial potential of autotrophic methylotrophs should be evaluated, especially in terms of the regulatory properties of the dissimilatory enzymes. The development of genetic techniques in these organisms will allow detailed study and manipulation of these key activities.

This research was supported by a fellowship from the Exxon Fducational Foundation and a grant from the National Institutes of Health (no. 5R01GH 27766).

\section{REFERENCES}

Anthony, C. (1982). The Biochemistry of Methylotrophs. London: Academic Press.

Anthony, C. \& Zatman, L. (1964). The microbial oxidation of methanol. 2. The methanol-oxidizing enzyme of Pseudomonas sp. M27. Biochemical Journal 92,614 621

ATTWOOD, M. \& QuaYLe, J. R. (1984). Formaldehyde as a central intermediary metabolite of methylotrophic metabolism. In Microhial Growth on $C_{1}$ Com- $^{-}$ pounds, pp. 315 323. Fdited by R. L. Crawford \& R. S. Hanson. Washington: American Society for Microbiology.

Bamforth, C. W. \& Quayle, J. R. (1978). Aerobic and anaerobic growth of Paracoccus denitrificans on methanol. Archices of Microbiology 119,91 97.

BEARDMORE-GRAY, M., O'KeEFFe, D. T.\& ANTHONY, C. (1982). The autoreducible cytochromes $c$ of the methylotrophs Methylophilus methylotrophus and Pseudomonas AM1. Biochemical Journal 207, 161 165.

BeARdmore-Gray, M., O'KeEFFe, D. T. \& ANTHONY, C. (1983). The methanol :cytochrome c' oxidoreductase activity of methylotrophs. Journal of General Microbiology 129, 923-933.

Boulton, C. A. \& Large, P. J. (1977). Synthesis of certain assimilatory and dissimilatory enzymes during bacterial adaptation to growth on trimethylamine. Journal of General Microbiology 101, 151-156.
Cox, R. B. \& Quayle, J. R. (1975). The autotrophic growth of Micrococcus denitrificans on methanol. Biochemical Journal 150, 569571.

Dunstan, P. M., Anthony, C. \& Drabble, W. T. (1972a). Microbial metabolism of $\mathrm{Cl}$ and $\mathrm{C} 2$ compounds. The involvement of glycollate in the metabolism of ethanol and of acetate by Pscudomonas AM1. Biochemical Journal 128, 99106.

Dunstan, P. M., Anthony, C. \& Drabble, W. T. $(1972 \mathrm{~b})$. Microbial metabolism of $C 1$ and $C 2$ compounds. The role of glyoxylate, glycollate and acetate in the growth of Pscudomonas AMI on ethanol and Cl compounds. Biochemical Journal 128. 107115 .

Fulton, G. F., Nunn, D. N. \& Lidstrom, M. F. (1984). Molecular cloning of a malyl coenzyme A lyase gene from Pseudomonas sp. strain AMI, a facultative methylotroph. Journal of Bactoriolog! $160,718-723$.

HaRder, W., ATtwood, M. M. \& Quayle, J. R.

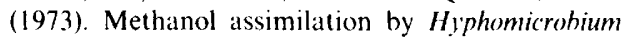
sp. Journal of General Microhiology, 78, 155163.

Johnson, P. A. \& Quayle, J. R. (1964). Microbial growth on Cl compounds. 6. Oxidation of methanol, formaldehyde and formate by methanol-grown Pseudomonas AMI. Biochemical Journal 93, 281-290.

Jones, C. W., Kingsbury, S. A. \& Dawson, M. J. (1982). The partial resolution and dye-mediated 
reconstitution of methanol oxidase activity in Methylophilus methylotrophus. FEMS Microbiology. Letters 13, 195-200.

Kasprzak, A. A. \& SteEnKamp, D. J. (1983). Localization of the major dehydrogenases in two methylotrophs by radiochemical labeling. Journal of Bacteriology 156, 348-353.

Kelly, D. P. \& Wood, A. P. (1982). Autotrophic growth of Thiohacillus A2 on methanol. FEMS Microbiology Letters 15, 229-233.

LAEMMLI, U. K. (1970). Cleavage of structural proteins during the assembly of the head of bacteriophage T4. Nature, London 227, 680-685.

Lidstrom-O'ConNor, M. E., Fulton, G. L. \& Wopat, A. F. (1983). 'Methylohacterium ethanolicum': a syntrophic association of two methylotrophic bacteria. Journal of General Microbiology 129, 3139 3148 .

Loginova, N. V. \& Trotsenko, Yu. A. (1979). Autotrophic growth on methanol by bacteria isolated from activated sludge. FEMS Microbiolog. Letters 5, 239-243.

MCNERNEY, T. \& O'CONNOR, M. L. (1980). Regulation of enzymes associated with $C-1$ metabolism in three facultative methylotrophs. Applied and Enrironmental Microbiology 40, 370-375.

Marison, I. W. \& ATtwood, M. M. (1980). Partial purification and characterization of a dye-linked formaldehyde dehydrogenase from Hyphomicrobium X. Journal of Generat Microbiology 117, $305 \cdot 313$.

MARison, I. W. \& ATTWOOD, M. M. (1982). A possible alternative mechanism for the oxidation of formaldehyde to formate. Journal of General Microhiolog. 128, $1441-1446$.

Muller, U., Willnow, P., Ruschig, U. \& Hopfner, T. (1978). Formate dehydrogenase from Pseudomonas oxalaticus. European Journal of Biochemistry 83, 485498.

Nealson, K. H. (1977). Autoinduction of bacterial luciferase: occurrence, mechanism and significance. Archires of Microbiology 112, 73-79.

O'CONNOR, M. L. (1981). Extension of the model concerning linkage of genes coding for C-1-related functions in Methylohacterium organophilum. Applied and Emironmental Microbiolog! 41, 437441.

O'Connor, M. L. \& Hanson, R. S. (1977). Enzyme regulation in Methylohacterium organophilum. Journal of General Microhiologi 101, 327-332.

O'KeEFFE, D. T. \& ANTHONY, C. (1980). The two cytochromes $c$ in the facultative methylotroph Pseudomonas AM1. Biochemical Journal 192, $411-$ 419.

Platt, T. (1981). Termination of transcription and its regulation in the tryptophan operon of E. coli. Cell 24, 1023.

SAHM, H., CoX. R. B. \& Quayle, J. R. (1976). Metabolism of methanol by Rhodopseudomonas acidophila. Journal of General Microhiolog! 94. 313 322.

URAKAMI, T. \& KomaGaTa, K. (1981). Electrophoretic comparison of enzymes in the Gram negative methanol-utilizing bacteria. Journal of General and Applied Microbiolog! 27, 381-403.

Van Verseveld, H. W. \& Stouthamer, A. H. (1978). Electron-transport chain and coupled oxidative phosphorylation in methanol-grown Paracoccus denitrificans. Archires of Microbiology 118, 1320.

Weaver, C. A., Redborg, A. H. \& Konisky, J. (1981). Plasmid-determined immunity of Escherichia coli $\mathrm{K}-12$ to colicin $1 \mathrm{a}$ is mediated by a plasmid-encoded membrane protein. Journal of Bacteriology 148, 817 828.

Wiegel, J., Wilke, D., Baumgarten, J., Opitz, R. \& Schlegel, H. G. (1978). Transfer of the nitrogen fixing hydrogen bacterium Corynebacterium autotrophicum Baumgarten et al. to Xanthobacter gen. nov. International Journal of Systematic Bacteriolog! $\mathbf{2 8}$, 573581 . 